\title{
Correction to: Paclitaxel-Coated Balloon Angioplasty \\ for the Treatment of Infrainguinal Arteries: 24-Month Outcomes in the Full Cohort of BIOLUX P-III Global Registry
}

\author{
Gunnar Tepe $^{1,11}$ - Thomas Zeller ${ }^{2}$ Matej Moscovic ${ }^{3} \cdot$ Jean-Marc Corpataux $^{4}$. \\ Johnny Kent Christensen ${ }^{5}$ Koen Keirse ${ }^{6}$ - Giovanni Nano ${ }^{7} \cdot$ Henrik Schroeder $^{8}$. \\ Christoph A. Binkert ${ }^{9} \cdot$ Marianne Brodmann ${ }^{10}$
}

\section{Correction to: Cardiovasc Intervent Radiol (2021) 44:207-217 https://doi.org/10.1007/s00270-020- 02663-7}

The original version of this paper did not contain a list of BIOLUX P-III investigators. The purpose of this addendum is to acknowledge the contribution of all investigators who participated in the study.
The original article can be found online at https://doi.org/10.1007/ s00270-020-02663-7.
Collaborators: BIOLUX P-III Global Registry Investigators: Marianne Brodmann, Thomas Zeller, JeanMarc Corpataux, Matej Moscovic, Gunnar Tepe, Koen Keirse, Giovanni Nano, Johannes B. Dahm, Johnny Kent Christensen, Reza Ghotbi, Christoph Binkert, Henrik Schröder, Denis Henroteaux, John Wang Chaw Chian, Eric Rosset, Enrique Alejandre Lafont, Sabrina Houthoofd, Miguel Araujo; Shaiful Azmi Yahaya, Don Robertson, Martin Freund, Lonneke Yo, Uei Pua, Roxanne Wu, Frank Hammer, Michael Lichtenberg, Janne Korhonen, Della Schiava, Ralf Langhoff, Stefano Michelagnoli, Secundino Llagostera, Jose-Maria Romero, Max Amor, Daniel Kret-

Henrik Schroeder

henrik.schroeder@ihre-radiologen.de

Christoph A. Binkert

Christoph.Binkert@ksw.ch

Marianne Brodmann

marianne.brodmann@medunigraz.at

1 Department of Radiology, Klinikum Rosenheim, Rosenheim, Germany

2 Clinic Cardiology and Angiology II, UniversitätsHerzzentrum Freiburg - Bad Krozingen, Bad Krozingen, Germany

3 Angiology Clinic, Institute of Cardiovascular Diseases, Kosice, Slovakia 
zschmar, Steven Kum, Patrice Mwipatayi, Albert J Smeets, Francisco Javier Serrano Hernando, Jost Philipp Schäfer, Gil Marques, Jos C. van den Berg, Ramesh Velu, Karlis Kupcs

Open Access This article is licensed under a Creative Commons Attribution 4.0 International License, which permits use, sharing, adaptation, distribution and reproduction in any medium or format, as long as you give appropriate credit to the original author(s) and the source, provide a link to the Creative Commons licence, and indicate if changes were made. The images or other third party material in this article are included in the article's Creative Commons licence, unless indicated otherwise in a credit line to the material. If material is not included in the article's Creative Commons licence and your intended use is not permitted by statutory regulation or exceeds the permitted use, you will need to obtain permission directly from the copyright holder. To view a copy of this licence, visit http://creativecommons. org/licenses/by/4.0/.

Publisher's Note Springer Nature remains neutral with regard to jurisdictional claims in published maps and institutional affiliations.
4 Department of Vascular Surgery, Lausanne University Hospital, Lausanne, Switzerland

5 Department of Radiology, Kolding Hospital, Kolding, Denmark

6 Department of Vascular Surgery, Regional Hospital Heilig Hart, Tienen, Belgium

7 1st Vascular Surgery Department, IRCCS Policlinico San Donato, San Donato Milanese, Italy

8 Center for Diagnostic Radiology and Minimally Invasive Therapy, Jewish Hospital, Berlin, Germany
9 Radiology Institute, Kantonsspital Winterthur, Winterthur, Switzerland

10 Division of Angiology, Department of Internal Medicine, Medical University Graz, Graz, Austria

11 Institut für Diagnostische Und Interventionelle Radiologie, RoMed Klinikum Rosenheim, Pettenkoferstr. 10, 83022 Rosenheim, Germany 